\title{
The Politics of Mental Illness and Involvement-A Discourse Analysis of Danish Anti-Stigma and Social Inclusion Campaigns
}

\author{
Jeppe Oute ${ }^{1}$, Lotte Huniche ${ }^{2}$, Connie T. Nielsen ${ }^{3}$, Anders Petersen ${ }^{4}$ \\ ${ }^{1}$ Department of Psychology and Behavioural Sciences, Centre for Alcohol and Drug Research, Aarhus University, \\ Aarhus, Denmark \\ ${ }^{2}$ User Perspectives, Institute of Public Health, University of Southern Denmark, Odense, Denmark \\ ${ }^{3}$ Psychiatric Department Kolding-Vejle, Region of Southern Denmark, Denmark \\ ${ }^{4}$ Department of Sociology and Social Work, Aalborg University, Aalborg, Denmark \\ Email:jo.crf@psy.au.dk
}

Received 5 October 2015; accepted 6 November 2015; published 9 November 2015

Copyright (C) 2015 by authors and Scientific Research Publishing Inc.

This work is licensed under the Creative Commons Attribution International License (CC BY).

http://creativecommons.org/licenses/by/4.0/

\section{(c) (i) Open Access}

\section{Abstract}

The present study is a part of a broader multisited field study on involvement of relatives in Danish psychiatry. The article aims to elucidate which political classifications of normality and mental illness that are displayed in two health political campaigns regarding anti-stigmatization and social inclusion and how such classifications co-constitute the subjectivity of individuals suffering from mental illness and their relatives. Drawing on a discourse theoretical perspective laid out by political theorists Laclau and Mouffe, we analyze how the campaigns bring into effect a weak and ineffective subject of deviance and how it is constituted by a subject of normality characterized by opposing traits. The article takes up the discussion of how the campaigns' articulations of the subjects of normality and deviance are imbedded in a hegemonic discourse of neoliberalism and individualism that asserts involvement as an expanded division of responsibility for the identification, classification and regulation of mentally ill subjects between public and private spheres of the Danish welfare state.

\section{Keywords}

Mental Illness, Involvement, Field Work, Discourse Analysis, Neoliberalism, Individualism

\section{Introduction}

This analysis investigates issues of classification and constitution of subjectivity in materials from two Danish

How to cite this paper: Oute, J., Huniche, L., Nielsen, C. T., \& Petersen, A. (2015). The Politics of Mental IIIness and Involvement-A Discourse Analysis of Danish Anti-Stigma and Social Inclusion Campaigns. Advances in Applied Sociology, 5, 273-285. http://dx.doi.org/10.4236/aasoci.2015.511026 
anti-stigma and social inclusion campaigns regarding mental illness and involvement; respectively called "En af Os” and "PsykiskSårbar” which translate into "One of Us" (One of Us, 2014) and “Mentally Vulnerable” (The Social Network, 2014). The article emerges from a broader, multisited field study, the aim of which is to shed light on the constitutive conditions for, and consequences of, involvement of relatives in psychiatric treatment and rehabilitation. In line with a multisited research strategy initially laid out by anthropologist Marcus (Marcus, 1998) and further developed by anthropologists Shore and Wright (Shore, Wright, \& Però, 2011), the main author (JO) traced discursive articulations and metaphors of mental illness and measures and ideals for involvement that connected three types of empirical sites across the Danish psychiatric system. Specifically, signs of weakness and deficits, and symbols of responsibility and effectiveness that constituted involvement were traced from the families' daily lives into the professional practices at two psychiatric hospitals and, further, to the websites of several non-governmental organizations (NGOs) and welfare state organizations amongst which a large body of policies were collected. As the campaign materials both reflected the official discourse of the two psychiatric hospitals' and the official engagements in involvement of the Danish welfare state, the campaign materials were specifically singled out for this investigation in order to elucidate the overall health political conditions for involvement and social inclusion in the psychiatric field.

Involvement campaigns form an important part of overarching political strategies for the future development of the psychiatric system and health care practice in Denmark (Danske Regioner [trans. Danish Regions], 2009). According to the Governmental Committee on the future organization of Danish psychiatry (GCP), they reflect current developments in the national and regional prevention and treatment policy aimed at the recovery of individuals suffering from mental illness (Udvalget [trans. The Governmental Committee on the future organization of Danish psychiatry (GCP)], 2013). According to Shore and Wright, such political campaigns may work as powerful instruments for social change that governments and NGOs use to constitute the identification, classification and regulation of the subjects they seek to govern (Shore et al., 2011). As a pivotal element in these new health political developments in Danish psychiatry, the campaigns can be seen as an organizing principle that provides specific ways of conceptualizing social relations between groups of citizens, such as individuals suffering from mental illness, their relatives and health care professionals (Shore et al., 2011). However, a policy is not necessarily considered as external, or constraining forces, and nor are they confined to texts. Instead, we will use the following understanding of policy: “As a lens through which to study processes of political transformation, the field of research becomes not a particular people or organization-far less a reified policy itself-but a 'social and political space articulated through relations of power and systems of governance"” (Shore et al., 2011: p. 11). The analysis of political campaigns, such as "One of Us" and "Mentally Vulnerable”, may therefore elucidate the political classification to which the target individuals are subjected, and how the campaigns constitute specific processes of subjectification of political citizens. Rather than considering how clinical professionals and individuals who experience distress and their relatives articulate involvement, this analysis specifically highlights what political order the campaign materials come to instigate for them (Shore et al., 2011). As such, this article aims to elucidate which political classifications of normality and mental illness are portrayed in the campaign materials and how such classifications co-constitute the subjectivity of individuals suffering from mental illness and their relatives. In doing so, the study considers how the discourse of involvement is constituted by more resident articulations of mental illness and normality. In this sense, the analysis and the critical considerations that follow are aligned with sociological perspectives on deviance and normality rooted in the structuralist idea that different politics, ideals and values and mental illness, such as depression, are mutually constitutive of each other in a society (Kleinman, 1995; Fullagar \& O’Brien, 2013; Busfield, 2000).

\section{The Construction of Mental Illness as a Matter of Weakness}

Previous studies have pointed to the fact that dominant notions of mental illness are embedded in broader cultural constructions of weakness or vulnerability in the psychiatric field in Scandinavia. In a narrative study on involvement processes, it was identified that cohabitant relatives of depressed individuals classified their ill partner as being a weak character. The combination of the relatives' classification of their partner and the professional ways of holding the relatives responsible for psychiatric treatment constituted a moral necessity for the relatives to control the ill person's weakness. However, this rationale eventually led to conflict and relational strain in the suffering families, due to the relatives' considerable efforts to control their partner's weakness (Hansen \& Buus, 2013). Moreover, a previous discourse analysis of the most widely used Danish textbook on mental health nursing in Denmark combined with field observations and interviews with psychiatric profession- 
als elucidated that a comparable, professional rationale about mental illness was at stake in clinical practice: In contrast to a weak, childlike and male patient, the hegemonic articulation of the nurse placed her/ him in the position of a dominant and all-knowing mother-figure; a position labelled as a "Hege-mom". This work made it clear that the subject of the patient served as a constitutive premise for the articulation of the indispensability of the subject of the nurse in the psychiatric field, because the "Hege-mom", in opposition to the subject of the doctor, is presented as someone that truly and intuitively understands the patient's personal weakness and deficiencies (Oute Hansen \& Randwijk, 2015). Moreover, based on lengthy ethnographic fieldwork in psychiatric settings, Jacobsen (Bredahl Jacobsen, 2006) and Øvre Sørensen (Øvre Sørensen, 2006) both referred to the professional discourse of psychiatric nursing staff. This discourse drew on psychoanalytic signs of the patients' weakness that constituted and legitimized a hierarchical order of ruling amongst the professionals and the psychiatric patients. In a Norwegian context, Øye et al. equally pointed out that the psychiatric care and treatment are organized based on parallel psychodynamic notions of the patient as a weak, vulnerable and childlike subject (Oeye, Bjelland, Skorpen, \& Anderssen, 2009). Furthermore Øye et al. have shown that the underlying medical-ethical rationale in the psychiatric field in Norway is based on articulations of the patient as weak or vulnerable, because national policies for this field and the medical ethical committee system signal consent to this rationale (Oeye, Bjelland, \& Skorpen, 2007). Overall, these studies point out that weakness works an inherent part of the classification of mental illness in Scandinavia. This constitutional premise frames the legitimacy of conducting care for, and control of, the weaknesses of mentally ill subjects in rather paternalistic ways. The dominant consent to the belief, that mental illness reflects personal weakness, thus works as an important premise for involvement across public and private contexts of psychiatric systems in Scandinavia. However, these notions of weakness and their constitutive effects are embedded in, and constituted by, much broader hegemonic articulations of normality in neo-liberal societies that, taken together, symbolically set the premises for what involvement can be considered to encompass. Moreover, similar studies of discourses of websites and policies have shed light on, how the understanding of mental illness as a matter of weakness is embedded in a dominant discourse about cost-effectiveness, responsibilization and self-reliance in psychiatric systems across contemporary, neo-liberal, Western societies (Carney, 2008; Fullagar, 2009; Ramon, 2008; Teghtsoonian, 2009). However, such study has to our knowledge not been conducted in a Scandinavian context. By conducting this analysis on subjectification processes, we wish to raise questions about how such political campaigns conceptualize classifications of normality and deviance and what regulatory processes of involvement they may instigate for professionals and families experiencing mental distress. Moreover, we wish to consider the normative or moral conception of the social subject established by the discourse and the possible consequences of this conceptualization.

\section{Methodology}

The overall, multisited fieldwork took place between October 2011 and April 2013 in the Region of Southern Denmark. It began at two psychiatric outpatient clinics where individuals diagnosed with affective disorders were in treatment. Based on materials from two anti-stigma and social inclusion campaigns found at these clinical sites, signs and symbols of involvement were further traced on to the political sites consisting of numerous virtual governmental and NGOs' websites including the "One of Us" and "Mentally Vulnerable" campaigns.

The two campaigns were highly noticeable in both of the clinical sites as well as in all the political websites. For example on arrival at both of the two psychiatric hospitals, a banner for the anti-stigma and social inclusion campaign "One of Us" had been erected in a prominent position at both hospital entrances. Various advisory leaflets and postcards, targeted at patients, relatives and professionals were on display (One of Us, 2014). The leaflets and postcards referred to the campaign website from where there was a link to "The Social Network", which had previously launched a resembling sister campaign called "Mentally Vulnerable" (The Social Network, 2014). The materials from the "Mentally Vulnerable" campaign were included in our analysis, because the campaigns are closely related and designed to mutually reinforce each other. The large-scale political support for both of the campaigns was made evident by the organizations that gave their backing. These included the Danish Health and Medicines Authority, the Ministry of Social Affairs and Integration, Danish Regions and a wide range of psychiatric user organizations and corporate foundations, such as the Depression Association, Better Psychiatry, the Danish Mental Health Foundation and the Danish foundation called TrygFonden ${ }^{1}$. As the

\footnotetext{
${ }^{1}$ TrygFonden is a Danish not-for-profit organization that funds research. It is part of the health, security and insurance corporation called TryghedsGruppen, which holds $60 \%$ of the shares in the Danish insurance company Tryg.
} 
two campaigns elapse between 2009 and 2015, and are supported by multiple governing and non-governing health and social work organizations in Denmark, the eye-catching promotional stands reflected the official discourse of the psychiatric hospitals' health political engagement and efforts in involvement (Psykiatrien i Region Syddanmark [trans. Psychiatry in the Region of Southern Denmark], 2014). Whereas the abovementioned fieldwork particularly included families with a person diagnosed with moderate to severe depression, the politically driven campaigns targeted a much wider selection of the population, including volunteers such as relatives, professionals, employers, media workers and members of NGOs and political organizations-all of whom had relations to individuals experiencing mental distress in the broadest sense (The Social Network, 2014; One of Us, 2014). The fact that the campaigns were prominent at the two empirical sites is an indication at these two psychiatric organizations have formally taken on, or at least support, the subjectification processes constituted by the general policy expressed through the campaigns (Psykiatrien i Region Syddanmark [trans. Psychiatry in the Region of Southern Denmark], 2014).

\section{Materials}

We based our analysis on electronically imported text materials from the front pages and sub-menus of the websites where the campaign backgrounds and formalized materials were presented. The materials included the campaigns' official materials, which predominantly entailed descriptions of political aims and a range of individuals' statements about the aims and objectives of the campaigns. We excluded the websites' forums for users' personal stories, because our focus was on the official health political notions of normality and mental illness. From the "One of Us" campaign, we included the front page and the items: "About the Campaign", "Become wiser", "Breaking the silence" and "Become one of us" (One of Us, 2014). From the "Mentally Vulnerable" campaign website, we included the front page, "About the social network", "The Mirror", "Vulnerable", "Relatives", "Knowledge about diagnoses" and "Activities" (The Social Network, 2014). In total, the material consists of some 400 pages, downloaded in June 2013. Translations of Danish text materials from the websites were carried out by the first and second author and then proof read by a professional translator in cases where English versions of the materials were not available. Bearing the purpose of the article in mind, the campaign materials were read in full and then line coded into twenty-one folders. Subsequently, the folders were clustered into two categories-signifiers of weakness and signifiers of ineffectiveness-that were adjusted until the categories appeared coherent with the entirety of the material. The open-ended coding of the materials was managed using NVivo 9.0 software.

Because this critical analysis of political subjectivities and involvement processes is grounded in what can be labelled constructivist ethnography (Marcus, 1998; Shore et al., 2011), we found it coherent to draw on a notion of discourse and subjectivity set out by political theorists Ernesto Laclau and Chantal Mouffe (Laclau \& Mouffe, 2001). Through this theoretical lens, discourse is understood as articulation encompassing "any practice establishing a relation among elements such that their identity is modified as a result of the articulatory practice" (Laclau \& Mouffe, 2001: p. 105). Discourse theory works particularly well to help clarify how articulations structure political subjectivities and social processes within the field of the social according to the dominant political classification of normality and deviance (Laclau \& Mouffe, 2001; Torfing, 1999). Our approach to subjectivity and involvement is thus founded on the claim that "the social" can be understood as a symbolic order constitutive of the organization of meaning (Shore et al., 2011; Marcus, 1998). As such, we consider constitutional processes, such as subjectification and involvement, as social, structural concerns (Marcus, 1998; Shore et al., 2011). In doing so, we hypothesize that discursive structures of language, encompassing both verbal and material signs and expressions, constitute the practices of involvement. The meaning of this practice is brought into effect by dominant ways of signifying mentally ill and relative subjects (Torfing, 1999; Laclau \& Mouffe, 2001). This analytical lens relies on an anti-essentialist understanding of the subject. That is, the subjects are decentered and hence considered as positioned effects of the symbolic structure in which they contrast each other. The subjects' perspectives, practical possibilities and social mobility are thereby structured accordingly (Shore et al., 2011).

\section{Discourse Analysis}

The coding and the subsequent discourse analysis clarify how a dominant notion of involvement is discursively articulated by drawing on symbols of weakness and ineffectiveness. The articulation enables a specific understanding of a subject of deviance-a subject symbolizing mentally ill people. It places the deviant subject in 
contrast to a subject of normality-which symbolizes a relative or significant other such as a spouse, friend or health care professional. The discourse of involvement frames how these subjectivities ought to be concerned with classification and regulation of the deviant subject.

\subsection{Division of Normality and Deviance}

The signifier of normality is the starting point for the articulation of the two subject positions of normality and deviance, because it implicitly indicates that there is a normal "us" and a mentally weak "them".

Pivotal examples of this signifier were identified in the slogans of the "Mentally Vulnerable" and "One of us" campaigns (The Social Network, 2014; One of Us, 2014) because they draw up boundaries between the two categories of normality and deviance. The "One of Us" slogan echoes the chorus chant "[...] gooble gobble, gooble gobble. One of us, one of us. We accept here, we accept her. One of us [...]" from the wedding feast song in Tod Browning's horror film Freaks (Browning, 1931). In Browning's provocative horror film, the traditional figure of a trapeze beauty in a travelling circus, by the name of Cleopatra, marries a freak-little Hans, who displays a range of disabilities. Cleopatra plans to deceive and poison Hans to claim his considerable inheritance. During their wedding feast, the freaks chant the abovementioned song to invite Cleopatra to identify with their deviance. However, Cleopatra reacts with discomfort and rage, because she never intended to identify with the Freaks. She responds to their chant by degrading the deviant wedding guests with reference to discrediting classifications of them as a group. The film effectively draws up categories of "normal" and "deviant" and then proceeds to endow the deviant with the power to recast a member of the normal to become one of them. The film not only questions common ways of distinguishing between deviance and normality, it also raises the issue about who has the power to classify and regulate deviance. The campaign slogan thus highlights the fact that the slogans implicitly echo a similar contrast between normality and deviance as suggested by Browning and challenged in his film. In defining the categories of deviance and normality, the campaign articulations signify how the two opposing subject positions, the normal and the deviant, emerge through coherences of signs of weakness or strength and ineffectiveness and effectiveness.

In the following excerpt from the "One of Us" website, weakness both symbolizes the deviant subject's characteristics and signals its division from the normal subject:

"Maria Bødiker is tall, fit and healthy-looking. She seems strong and well-functioning. Her three kids look strong and well-functioning - and they are. They live in a good, well-furnished flat in one of the best parts of the town of Aarhus. So far, so good. There is just the important detail that Maria Bødiker is suffering from post-traumatic stress disorder."

The quotation suggests that the subject is characterized by weakness as an individual and an essential trait that predicts the subject's functioning, health, motherhood and everyday life, in spite of the fact that her everyday life and functioning appear to be normal. The contrast to the subject's weakness is emphasized using the verb "seem". Moreover, the final punch-line demonstrates that the subject's weakness is classified and outlined as post-traumatic stress disorder (PTSD). By emphasizing the contrast to the strength of the subject's children, it is articulated that her strength is not to be taken at face value, because she is suffering from PTSD, which constitutes Maria as a mentally ill subject. In line with the abovementioned headlines displaying the separation of normality and deviance, the mentally ill subject is discursively structured as being essentially incapable of being an effective and functioning subject [e.g., mother] and worker. In doing so, the subject is presented as essentially weak by suggesting that its mental illness or weakness is caused by a deprivation of its true, strong self that predicts the subject's incapability to perform or function as a mother and healthy and effective citizen. As such, the articulation of a division of normality and mental deviance is articulated more specifically by drawing on signifiers of weakness, and as we shall see below, ineffectiveness.

\subsection{Classification of the Weak Subject}

In spite of the variations in the emergence of the signifier of weakness, weakness was implicitly laid out in contrast to a strong, normal subject in the campaign materials. A frontline example of the signifier of weakness was identified in the slogan from the "Mentally Vulnerable" campaign. Across the materials, the sign of vulnerability or weakness signalleda deeply rooted individual and essential weakness of the subject. As such, the signifier acquired its more specific meaning through the articulation of different but widely used metaphors representing 
weakness. One example of the kind of metaphors used in the materials comes from the "Mentally Vulnerable" campaign. The metaphysical signifier "scarred soul” reflects the assumption that the ill subject essentially suffers from a lack of strength to endure something that already has or might hurt the weak subject's being or self. Drawing on the signifier "soul”, weakness is signified as a classification that concerns the subject's ontology. In this sense, the metaphorical signifiers suggest that the classification of the weak subject's self or very being relies on a contrast to the essence or core of the subject of normality that originates in a metaphysical ideal for the true being; the weak subject is thus constituted by an implicit ideal for how it ought to be. This suggests that the signifier of weakness works as a dominant sign in the articulation of how the deviant subject's being essentially suffers from an ill core. This determines its illness and its lack of abilities and competencies to live "truly" that sets it apart from the normal subject. The specific signification of such essential conditions of the deviant subject emerged as an articulation of a range of shortcomings in the subject's social and personal qualities that effectuated specific forms of regulation of the weak subject.

The weak subject is represented as lacking social qualities, such as motivation and independence, self-reliance, responsibility and the ability to manage relations appropriately. In the following quotation from the "Mentally Vulnerable” campaign the weak subject is articulated:

"I have been too slow to seek out help and have been so messed up that I drank myself into a stupor and hid away under my quilt. And I have to be way-out there before I open up but I also know that there is help at hand when I dare to be weak. [...]. One must accept the help that is available. When one is suffering, you have to open yourself up-by daring to recognize that you are weak.”

The excerpt suggests that the weak subject is acting socially inappropriately due to its drunkenness and isolation. However, as the subject submits itself to the subject position of the deviant by confessing its weakness and need of help, the subject's initial irresponsibility, lack of motivation and inappropriate social qualities are outlined and relieved. This becomes evident because the subject's confession to these shortcomings contrasts an implicit idealized notion of normal behaviour that constitutes the weak subject's counterpart. Thereby, the quotation elucidates that the control of the subject's weak social qualities both entails and depends on its submission to the available help so that it can be normalized. Moreover, the quotation highlights how the subject's inappropriate behaviour, lack of responsibility, motivation and self-reliance counters what is considered as normal.

This behavioural deviance of the weak subject was articulated as being constituted by a range of personal shortcomings. These shortcomings were articulated as deficits in the subject's ability to recognize, feel, think and perform responsibly and appropriately.

As such, the weakness of the deviant subject was articulated as an incapability to have an appropriate degree of self-control. These traits are articulated in the following excerpt from the "One of Us" campaign, where the deviance of the subject Bjarne is presented:

"Bjarne did not have many friends, he drank too much, his finances were in a mess, and he had a poorly functioning relationship. One day he decided to do something about it. In 2009, on his own initiative, he was diagnosed with ADHD and Asperger's syndrome. Since then, he has organized his everyday life and working life according to his strengths and weaknesses.”

The quotation elucidates how Bjarne is articulated as a weak and irresponsible subject, because he lives an isolated life without many friends. His irresponsibility is signalled by his excessive drinking and his lack of control of his financial situation and his relationship. In this sense, the deviant subject is explicated in contrast to a responsible subject of normality that is supposed to take control of its weakness by recognizing that it is weak and irresponsible. As the quotation shows, the deviant subject complies with its weakness by recognizing its need to be diagnosed, freely and willingly. The proper functionality of a subject's everyday life, in terms of its marital and financial situation, is presented as resting on its ability to identify and recognize its own weaknesses. As such, the deviant subject is articulated in contrast to the subject of the normal. In this sense, the weak subject is implicitly described as someone who should be taking personal responsibility for its own well-being and effectiveness as a normal citizen by complying with a medical classification of its weakness.

Because the deviant subject is compelled to recognize and identify with the classification of weakness in order to become normalized, it is effectuated as a medicalized subject complying with its recognition of the classification of its weakness. The "Mentally Vulnerable" campaign articulated how the weak subject complied with the classification of its weakness and thus its need of medical treatment: 
"When I went to my GP, he found that I had clear signs of depression and he gave me antidepressants. I thought that I was cheating taking antidepressants. I could not tell anyone because I felt that I ought to do without them. But I have got to say that antidepressants are wonderful.”

The quotation articulates that the weak subject is effectuated as a medicalized subject-a subject that has willingly submitted to a medical understanding of its weak core and accepted antidepressants. The subject's weakness is articulated as its “clear signs of depression”. As such, the effectuation of the weak subject's medicalized position is constituted by its recognition of its weakness, and further compounded by its recognition of the need for medical regulation of its weaknesses, in that the subject "could not do" without the "wonderful” antidepressants. In this sense, the weak subject's essential lack of strength, self-control, responsibility and self-reliance legitimizes its medical regulation, because the subject's essential shortcomings predict its incapacity to function in an effective way. In this way, the regulation of the weak subject is legitimized by its lack of effectiveness.

\subsection{Regulating the Weak Subject}

In contrast to the normal subject, the articulation of the lack of effectiveness of weak subjects rests on an assumption that they are a stigmatized class of people excluded from taking part in societal activities, due to extensive lack of openness, knowledge and understanding of mental illness among all members of society. In the "Purpose and Vision” of the "Mentally Vulnerable” campaign, this is articulated in the following way:

"It is our wish that the dialogue and the information from the "Mentally Vulnerable" website contribute to the creation of a better understanding of mental vulnerability and not least openness-amongst the vulnerable, relatives, nursing staff, politicians, neighbours, colleagues and all others. [...] The dream is that, in the long term, we create a society where all humans-whether they have a vulnerability or not-have real opportunities to take part on equal terms with others.”

The quotation suggests that the weak subject is held in a marginalized and stigmatized position in society due to lack of openness and knowledge about the subject's weakness. Thus, the quotation indicates a rationale that suggests that openness and knowledge about the classification of weakness would enhance social inclusion, recovery and equality, and would counter the stigmatization of people suffering from mental illness, if only normalized vulnerables (weak subjects acting responsibly), relatives and all other citizens could understand and classify it. By suggesting that "all other" normal subjects should aid this process of subjectification of the weak subject, the text explicates the understanding that significant others are responsible for regulating the weak subject, by subjecting it to medical classifications and treatment for its deviance.

This process of regulation of the weak subject relies on a separation between normal and deviant subjects. The division is presented by drawing on signifiers from wide-ranging political efforts to divide responsibility for the identification, classification and regulation of the weak subject between public and private spheres in the Danish welfare state. In the following excerpt from the "One of Us" campaign, the Danish Member of Parliament and former minister of Health and Prevention, Astrid Kragh is quoted:

"Perhaps due to convenience, as a society we have built a wall around mental illness that stops us from seeing, recognizing and helping the people we know who have mental problems."

The signs "seeing”, “recognizing” and "helping” suggest that efforts to identify, classify and regulate the deviant subject's weakness is a moral concern regarding effective and precise diagnostic processes, treatment and normalization of the deviant. The articulation of "we" implies that normal subjects implicitly are, at least in part, supposed to be responsible for classifying and managing treatment of the weak subject in private contexts. This rationale encompasses that the responsibility for the identification, classification and regulation of weak subjects has expanded or shifted from a professional concern of the welfare state into an individual responsibility that users, relatives and employers must take on voluntarily. The discourse of involvement in the anti-stigmatization and social inclusion campaigns thus signals an expanded prevention and treatment strategy. This inherent rationale comprises efforts to divide the psychiatric labor involved with identification, classification and regulation of the weak subject between public and private contexts. By contrast to the weak subject, the discourse constitutes that the subject of the normal is considered as the subject that has true ability to "see" and "recognize" the weaknesses of the deviant subject. In this sense, the subject of the normal is constituted by its involvement with psychiatric labor related to the identification, classification and regulation of the subject of the deviant, because the weak subject is articulated as partially incapable of taking on these responsibilities competently and effec- 
tively.

In this sense, the campaigns not only set up a framework for the understanding of subjectivities of deviance and normality but also effectuate a legitimate order of ruling and control between the two subjectivities. Specifically, the regulation process of the campaigns implies that the deviant subject identifies with the classification from itself, relatives and others of significance. As such, the campaigns constitute that involvement of the subject of the normal, in direct or indirect contact with the weak subject, specifically entails a subtle but comprehensive form of social control, where the deviant subject is submitted to, and equally ought to submit itself to, constant surveillance. Conversely, the subject of the normal must commit itself to the position of the normal and thereby to the task of classifying and regulating the weakness and ineffectiveness of the deviant subject. Paradoxically, the division and symbolic effectuation of the two subjectivities excludes the subject of the weak from the class of the normal. None the less, this discursive constitution of the normal subject, and the ways in which it is involved with surveillance and control of the weak subject is articulated as legitimate.

The legitimacy of the campaigns' constitution of the process of involvement and regulation is articulated as a fundamental rationale of the campaigns. For instance, this overarching rationale gains its more precise meaning when it is articulated in the context of the expected social consequences of the stigmatization and exclusion of the weak subject, as articulated in the initial description of the ideals for the "One of Us" campaign:

"[Stigmatization] makes it hard to be ill and may be an obstacle for having a meaningful life, such as having labour market attachment. It might also prevent people from getting treatment in time. This comes at a high price. For the individual and for society."

The text highlights the campaigns' key assumption that stigmatization following lack of openness and understanding obstruct early identification and classification of weak subjects, which would counter mentally ill subjects' opportunities for having a meaningful and effective life. The articulation of the obstruction of the identification and classification suggests that the weak subject would be having a hard time creating a meaningful life, at least in part, because it is poorly integrated with the labour market, due to its lack of timely treatment. The rationale implies that the subject's opportunities for having a meaningful and cost-effective work life, rather than becoming a burden to society, rests on the subject's submission to medical classifications of its weakness and thus to compliance to medical treatment.

To sum up the elements of the discourse presented throughout this analysis, the articulations of the campaigns constitute a specific effectuation of the subject of the weak and of the subject of the normal that, at least primarily, is constituted by an overall aim to reduce societal costs by involving the subject of the normal. The discursive rationale of the campaigns relies on the suggestion that medical treatment would reduce personal and societal costs following mental illness, because the weak subject's compliance to treatment would regulate or normalize its ability to work. The discourse thus represents an effort to expand the responsibility for the identification, classification and regulation of what is implicitly understood as deviant and weak from a public and professional concern of the welfare state to a broad private and voluntary concern.

\section{Discussion}

Working from a discourse theoretical perspective, this critical analysis calls for a reflection on how the understanding of mental illness is framed by symbols and signs of ineffectiveness. Below, we will broaden the discussion of the abovementioned local perspectives by arguing that the articulation of mental illness as a matter of weakness is embedded in a hegemonic discourse about cost-effectiveness, responsibilization and self-reliance in psychiatric systems across contemporary, neo-liberal, Western societies (Ramon, 2008; Carney, 2008). Subsequently, we will consider the kinds of new problems and questions that arise from this rationale.

\subsection{A Hegemonic Discourse of Normality, Mental Illness and Involvement}

The political scientist Jacob Torfing, who has written extensively about the theoretical foundations and implications of discourse theory and hegemony, states that: "hegemony is just another name for politics, but one which emphasizes the construction of identity, and conceives values and beliefs as an integral part of such an identity" (Torfing, 1999: p. 82). By highlighting the theoretical underpinnings for our enquiry into hegemony, Torfing continues to lay out the concept as: "the expansion of a discourse or set of discourses, into a dominant horizon of social orientation and action [...]" (Torfing, 1999: p. 101). The dominant consent to a political structure constitutive of specific values thus becomes "the result of articulation" (Torfing, 1999: p. 101). By discussing the 
Marxist foundations of discourse theory, Torfing warns discourse analysts about the risk of overemphasizing how hegemonic forces would constitute ideological and economic subjectivities and social order on behalf of the state when analyzing articulatory practices (Torfing, 1999). As such, our analysis requires critical reflection or, at least, a cautious attitude towards the social contingency of the discourse of mental illness and involvement. Such precautions imply reflections on how hegemonic articulations may be contested by antagonistic articulations of users', relatives' and families' voices; opposing discourses that are singled out based on the different part of the main study mentioned above. Thus, in order to clarify and disentangle the similar and diverging understandings of involvement of political intuitions, professionals and families, these discursive understandings are investigated in turn. That being said, it could have added colorful nuances to the imagery of the landscape of involvement to consider, how the campaign websites' forums of users' personal stories, which were excluded from the present analysis, could yield a contestation of the analysis of campaigns' official notions of normality and involvement. Despite these considerations, we maintain that the articulations of the campaigns signal a hegemonic discourse in the Danish psychiatric field today, because the campaigns represent the voice of several governing bodies and psychiatric institutions in Denmark.

Thus, we argue that this analysis highlights how these health political campaigns represent a hegemonic discourse about normality, mental illness and involvement. To a large extent, the rationale about mental illness as a matter of weakness rests on the consent with an ideological notion of effectiveness that constitutes how professionals, users and relatives consider and practice treatment and involvement in contemporary Danish psychiatry. Our abidance to the hegemony of the presented discourse is concerned with weakness signaling and effectuating the opposite of a notion of subjectivity deeply rooted in the moral and ideology of neo-liberalist virtues and work ethics of individualism in Western industrialized countries (Fullagar, 2009; Teghtsoonian, 2009). These impinge on the individual's responsibility for, and capacity to be actively engaged with managing one's freedom and self-reliance and being a cost-effective citizen (Fullagar, 2009; Barry, 1996). In this sense, the internal coherence of signs in the campaigns' discourse means that the deviant subject is presented as essentially incapable of performing responsibly, self-reliably and effectively as a citizen, because the discourse characterizes it ineffective and weak. As previously shown by the English sociologist Nikolas Rose (Rose, 2007; Rose, 1999), the present analysis clarifies how the ideological and ethical foundations of psychiatric classifications frame the legitimization of the subtle forms of social control that have come to be an inherent part of the development of contemporary psychiatry. Thus, the analysis both sheds light on the moral landscape of contemporary understandings in society but, equally importantly, it elucidates that individualism constitutes how deviant subjects are articulated as implicitly guilty of being a societal burden. Hence, the neo-liberal and individualistic ideal of the subject of normality frames how the shortcomings and ensuing cost-ineffectiveness of the deviant subject legitimizes why and how the subject of the deviant must subject himself or herself to the processes of identification and classification of his or her lack of self-reliance, effectiveness and responsibility. Such tendencies to classify and maintain problems of living and misery as individual concerns could, however, be seen as a reflection, and perhaps even a necessity, of the neo-liberal morals of contemporary Western societies (Moncrieff, Rapley, \& Dillon, 2011). From a historical and sociological perspective, the social scientists Anders Dræby Sørensen (Dræby Sørensen, 2002) and Alain Ehrenberg (Ehrenberg, 2010) have argued that the illness of depression represents the moral negation of contemporary Western society. In a slightly provocative Danish study, Dræby Sørensen (2002) argues that depressed individuals are considered as "living dead", because they represent the negation of contemporary ideals for happiness and life itself. Previously, Ehrenberg (2010) questioned the notion of mental illness by arguing that the categories of melancholia, neurasthenia, neurosis and delusions have conditioned the development of the classification of mental illness that has come to represent a lack of the neo-liberal ideals of autonomy, responsibility, capacity to act and self-realization. This highlights how the campaigns' inherent neo-liberal virtues of life itself, characterized by self-realization, autonomy and responsibility, constitute a relationship between the normality and effectiveness of the "us" and the deviance and ineffectiveness of the "them". Despite the fact that these campaigns signal the essential ideals and measures for the reformation and de-institutionalization of Danish psychiatry (Udvalget [The Governmental Committee on the future organization of Danish psychiatry (GCP)], 2013), they paradoxically make possible an institutionalization and reproduction of an antagonistic social and moral order between the category of the normal and the category of the deviant (Torfing, 1999). As these political articulations constitute surveillance, subjectification and medical control of the mentally ill subject in private contexts, the discourse of the policies instead legitimizes involvement as a means or managerial technology of concealed moral coercion of subjects classified as weak. 


\subsection{Technologies of Governance of the Weak and Ineffective}

The campaigns' articulations of the involvement of ill subjects and their significant others do not work as an emancipatory effort to humanize psychiatric systems and treatment regimes in Denmark, as the "One of Us" headline might suggest. Rather, the campaigns serve as a wide-ranging, but subtle, prevention and treatment strategy aimed at governing the weak subjects at a distance by involving the normal, responsible and effective subjects, such as relatives, professionals or colleagues. The campaigns' systematic reproductive constitution of such moral order between the deviant and normal seems paradoxical, given that the campaigns are social inclusion and anti-stigma campaigns. The paradox concerns the fact that the ideological articulation of the weak and ineffective subject instead effectuates an underprivileged and stigmatized subject position of the weak. Rather than dissolving processes of stigmatization, exclusion, recovery and disenfranchisement, the campaigns both signal and frame of a very broad systemic form of stigma. This systemic or structural stigmatization entails an institutionalization of the reduction of opportunities of this particular group of people that are classified as weak and vulnerable. Then, systemic stigma is capable of structurally limiting the rights and relational possibilities of the people considered weak and vulnerable (Yang et al., 2007). Moreover, this stigmatizing articulatory process of the subject of the weak defines the principle of its regulation, because the articulation effectuates the subjectification of the weak or inappropriate subject. Even if this type of governance and public regulation does not primarily exert direct control over those deemed as mad, the campaigns' inherent and dominant understanding of mental illness as a matter of weakness does constitute a morally flawed, ineffective subject that must rely on comprehensive but subtle social restraint from those in its surroundings. Rather than signaling a normalizing transformation of the deviant subject, this work clarifies how political campaigns legitimize systematic regulation and exclusion of the weak subject. In this sense, this critical analysis highlights what has previously been outlined in the work of multiple scholars' and social scientists and other researchers on policy, subjectivity and governance (Shore et al., 2011; Kleinman, 1995). Such critique points out that these anti-stigma and inclusion campaigns work as neoliberal policies of governance that involve a specific constitution of the subjectivity of deviant subjects. As such, it sheds light on how the campaigns set up a framework for managing deviant subjects. The symbolic constitution of such management of deviant subjects thus signals a dominant political rationale of social control within the state of Denmark, which, paradoxically, is reproductive of the social issues it aims to resolve. Even if the headline of the "One of Us" campaign gives an immediate impression of effectuating of a more common notion of mental illness, they paradoxically imply the symbolic constitution of a rather narrow moral and ideological positioning of mentally ill subjects.

As described above, neoliberal ideology, a deficit model about mental illness and individualization work as decisive, symbolic aspects for the conception of involvement in Danish psychiatry. These aspects closely resemble the aspects and effects of recovery in psychiatry identified by UK psychologist, David Harper and sociologist, Ewen Speed (Harper \& Speed, 2014). Similar to the present analysis of Danish policy on involvement, their "uncovering of recovery" elucidates that recovery policy in the UK, US and other Western countries equates with neoliberal identity politics. Parallel to our analysis of involvement, recovery also relies on individualistic and medicalized notions of responsibility, on a deficit model about the etiology of mental illness and downplays any social context for mental distress beyond interpersonal problems (Harper \& Speed, 2014). With regard to individualization, their analysis resembles our discoveries, as they state that: "Neoliberal policies invite people to see certain problems [such as mental distress] as the responsibility of the individual rather than, for example, the state" (Harper \& Speed, 2014: p. 45). Moreover, by relying on a medical deficit model, the concepts of involvement and recovery both assert that the mental health problems are caused by weakness; characterized by a lack of ability for self-management, skills for living and working, opportunity for education, relationships, etc. All of these deficits are laid out as existing negatives with a potential to be transformed into positives; collective understandings of strengths. The meaning of the negative then depends on a positive, opposite term. Analogous to recovery (Harper \& Speed, 2014), involvement does not offer an alternative to the medicalized notion of mental illness, but rather endorses it. This is established by the fact that the campaigns reproduce and even institutionalize the use of the deficit model and an individualizing way of addressing the social inequality of stigmatized psychiatric service users. In doing so, the campaigns largely ignore an actual re-distribution of power and reproduce the structural (ideological or economic) conditions for distress.

\subsection{Implications and New Directions}

In conducting this analysis and subsequent discussion, we set out to clarify the social conditions for normality, 
deviance, subjectivity and involvement in two pivotal health political campaigns in psychiatry. By aiming to clarify the ideological and ethical foundations of the political classification of deviance and normality within the psychiatric field in Denmark, the present analysis provides a number of paradoxes concerning the reproduction of subjectivity and social order. As such, the analysis suggests that the present approach to mental health prevention may, in fact, sustain problems with mental illness. In this line of thought, the analysis indicates that the campaigns may even subject more people to the category of the weak and mentally ill. Then, this work calls for new perspectives in mental health promotion policy and research that make it possible to consider people's distress and their human condition. Accordingly, the present analysis and succeeding considerations have produced more questions than they answer. First, these clarifications raise questions about the political intentionality of the campaigns and whether or not these issues have been foreseen by the governing bodies producing them. For example, how are we to understand that Danish user organizations such as Better Psychiatry, which support the campaigns, represent such discrediting discourse about mental illness, when they specifically aim to improve the rights and possibilities of relatives and users (Bedre Psykiatri, 2014 [trans. Better Psykiatry])? Given that Danish user organizations draw on such discrediting discourse, who will represent users' voices and resistance in Danish psychiatry and how can user voices be heard and supported in both Danish policy and future research? In contrast, the British Psychological Society has recently put out a stigma-combatting policy by the name of "Understanding Psychosis and Schizophrenia - why people sometimes hear voices, believe things that others find strange or appear out of touch with reality, and what can help" (Division of Clinical Psychology, 2014). For instance, in the report it is articulated that it concentrates: “... on the psychological and social aspects, both in terms of how we understand these experiences and also what can help when they become distressing" (Division of Clinical Psychology, 2014: p. 5). Second, what does the campaigns' constitution of the reproduction of the subjects of deviance mean for the statistical prevalence and overall wellbeing of mentally ill people in Denmark? Third, because managerial policies, such as the present campaigns, provide a framework for professional practice (Shore et al., 2011), the clarification of the campaigns' organizing rationale points to the necessity of scrutinizing what social consequences the constitution of subjectivity might have and how such rationales may be negotiated in clinical practice as well as in families experiencing distress. For example, several Scandinavian studies highlight that the signifier of weakness serves as a dominant sign in the professional discourse of mental illness. The professional discourse constitutes a similar paradox, as the patient is simultaneously considered as weak and incompetent and personally responsible for its actions. As such, the professionals can legitimately demand that the patient submits him/herself to their classification of his/her weakness and treatment needs (Oute Hansen \& Randwijk, 2015). This work therefore raises queries about if or how the professional discourse of weakness can connect with such psycho-ideological classification of the campaigns. Such insight could shed further light on the hegemony and effects of political and professional discourse on mental illness within clinical practice today. Moreover, what happens if cohabitant relatives of depressed individuals could share such notions of their partner's weakness and subsequently take on responsibility for treatment and emotional care (Hansen \& Buus, 2013)? This analysis then points to the importance of a deeper understanding of when or how weakness connects with families' organization, division of labour and development of psychosocial burdens of living with mental illness and distress.

\section{Acknowledgements}

This study was supported by grants from the Research Foundation of mental health in the Region of Southern Denmark, Danish Nurses' Organization, Novo Nordisk Foundation, Health Foundation and the Faculty of Health Sciences, University of Southern Denmark. We owe great appreciation to Christian van Randwijk for his numerous insightful comments on this paper. We declare that we have no conflict of interest.

\section{References}

Barry, A. (1996). Foucault and Political Reason: Liberalism, Neoliberalism and Rationalities of Government. Chicago: University of Chicago Press.

Bredahl Jacobsen, C. (2006). Paradoksal psykiatri: Etnografiske analyser af samspillet mellem plejepersonale og patienter i dansk restpsykiatri. Copenhagen: Institute of Anthropology, University of Copenhagen.

Browning, T. (1931). Freaks. 117. Ref Type: Motion Picture.

Busfield, J. (2000). Introduction: Rethinking the Sociology of Mental Health. Sociology of Health \& Illness, 22, 543-558. http://dx.doi.org/10.1111/1467-9566.00219 
Carney, T. (2008). The Mental Health Service Crisis of Neoliberalism-An Antipodean Perspective. International Journal of Law and Psychiatry, 31, 101-115. http://dx.doi.org/10.1016/j.ijlp.2008.02.001

Danske Regioner [Danish Regions] (2009). En psykiatri i verdensklasse: Regionernes visioner for fremtidens psykiatri. København: Danske Regioner.

Division of Clinical Psychology (2014). Understanding Psychosis and Schizophrenia—Why People Sometimes Hear Voices, Believe Things That Others Find Strange or Appear out of Touch with Reality, and What Can Help.

Dræby Sørensen, A. (2002). Den biologiske psykiatris renæssance og det antidepressive menneske. Slagmark, 159-183.

Ehrenberg, A. (2010). The Weariness of the Self: Diagnosing the History of Depression in the Contemporary Age. 345.

Fullagar, S., \& O’Brien, W. (2013). Problematizing the Neurochemical Subject of Anti-Depressant Treatment: The Limits of Biomedical Responses to Women's Emotional Distress. Health (London), 17, 57-74. http://dx.doi.org/10.1177/1363459312447255

Fullagar, S. (2009). Negotiating the Neurochemical Self: Anti-Depressant Consumption in Women's Recovery from Depression. Health, 13, 389-406. http://dx.doi.org/10.1177/1363459308101809

Hansen, J. O., \& Buus, N. (2013). Living with a Depressed Person in Denmark: A Qualitative Study. International Journal of Social Psychiatry, 59, 401-406. http://dx.doi.org/10.1177/0020764012438478

Harper, D., \& Speed, E. (2014). Uncovering Recovery: The Resistible Rise of Recovery and Resilience. In E. Speed, J. Moncrieff, \& M. Rapley (Eds.), De-Medicalizing Misery II (pp. 40-57). London: Palgrave Macmillan. http://dx.doi.org/10.1057/9781137304667.0008

Kleinman, A. (1995). Writing at the Margin: Discourse between Anthropology and Medicine. Berkeley, CA: University of California Press.

Laclau, E., \& Mouffe, C. (2001). Hegemony and Socialist Strategy: Towards a Radical Democratic Politics (2nd ed.). London: Verso.

Marcus, G. E. (1998). Ethnography through Thick and Thin. Princeton, NJ: Princeton University Press.

Moncrieff, J., Rapley, M., \& Dillon, J. (2011). De-Medicalizing Misery: Psychiatry, Psychology and the Human Condition. Basingstoke: Palgrave Macmillan.

Oeye, C., Bjelland, A. K., \& Skorpen, A. (2007). Doing Participant Observation in a Psychiatric Hospital—Research Ethics Resumed. Social Science \& Medicine, 65, 2296-2306. http://dx.doi.org/10.1016/j.socscimed.2007.07.016

Oeye, C., Bjelland, A. K., Skorpen, A., \& Anderssen, N. (2009). Raising Adults as Children? A Report on Milieu Therapy in a Psychiatric Ward in Norway. Issues in Mental Health Nursing, 30, 151-158.

http://dx.doi.org/10.1080/01612840802557246

One of Us (2014). En af os [One of Us]. www.enafos.dk

Oute, J., \& Randwijk, C. V. (2015). “We Will Be Taking Over Now”-A Discourse Analysis of Subject Positions in Danish Psychiatry. Issues in Mental Health Nursing, Accepted for Publication.

Øvre Sørensen, N. (2006). I virkeligheden udenfor: Et dobbelt perspektiv på sygeplejerskers arbejde i en psykiatrisk institution. En analyse af magt, styrings-og selvstyrings teknikker. Roskilde: Institut for uddannelsesforskning, Forskerskolen i Livslang Læring, Roskilde Universitetscenter.

Psykiatrien i Region Syddanmark [trans. Psychiatry in the Region of Southern Denmark] (2014). Psykiatrien i Region Syddanmark. www.psykiatrieniregionsyddanmark.dk

Ramon, S. (2008). Neoliberalism and Its Implications for Mental Health in the UK. International Journal of Law and Psychiatry, 31, 116-125. http://dx.doi.org/10.1016/j.ijlp.2008.02.006

Rose, N. (1999). Governing the Soul: The Shaping of the Private Self (2nd ed.) London: Free Association Books.

Rose, N. (2007). The Politics of Life Itself: Biomedicine, Power and Subjectivity in the Twenty-First Century. Princeton, NJ: Princeton University Press. http://dx.doi.org/10.1515/9781400827503

Shore, C., Wright, S., \& Però, D. (2011). Policy Worlds: Anthropology and the Analysis of Contemporary Power. New York: Berghahn Books.

Teghtsoonian, K. (2009). Depression and Mental Health in Neoliberal Times: A Critical Analysis of Policy and Discourse. Social Science \& Medicine, 69, 28-35.

http://dx.doi.org/10.1016/j.socscimed.2009.03.037

The Social Network (2014). Psykisk saarbar [Mentally Vulnerable]. www.Psykisksaarbar.dk

Torfing, J. (1999). New Theories of Discourse: Laclau, Mouffe, and Zizek. Oxford: Blackwell Publishers. 
Udvalget, O. P. [The Governmental Committee on the Future Organization of Danish Psychiatry (GCP)] (2013). Enmoderne, Aaben og inkluderende indsats for mennesker med psykiske lidelser: Rapport fra Regeringens Udvalg om Psykiatri [A Modern, Open and Inclusive Effort for People with Mental Illnesses: A Rapport from the Danish Governmental Psychiatry Committee]. Regeringens Udvalg om Psykiatri.

Yang, L. H., Kleinman, A., Link, B. G., Phelan, J. C., Lee, S., \& Good, B. (2007). Culture and Stigma: Adding Moral Experience to Stigma Theory. Social Science \& Medicine, 64, 1524-1535. http://dx.doi.org/10.1016/j.socscimed.2006.11.013 